\title{
Time Variability of Bank Asset Volatility on Deposit Insurance Price
}

\author{
Yi-rong YING ${ }^{1,2 *}$, Wei-yi ZHANG ${ }^{1}$, Meng-le GU ${ }^{1}$ and Yuya WANG ${ }^{3}$ \\ ${ }^{1}$ School of Economics, Shanghai University, Shanghai, 200444, China \\ ${ }^{2}$ Xianda College of Economics and Humanities, Shanghai International Studies University, \\ Shanghai \\ ${ }^{3}$ College of Sciences, Shanghai University, Shanghai, 200444, China \\ ${ }^{*}$ Corresponding author, yrying@staff.edu.cn
}

Keywords: Time-varying volatility; Deposit insurance price; B-S formula

\begin{abstract}
The deposit insurance price comprehensively reflects the possibility of bank default and can be regarded as an excellent measure of individual bank risk. However, how to combine it with the time variability of bank asset volatility is a difficult problem, so it is still necessary to carefully verify its rationality. We have verified the B-S model and the GARCH model from the perspective of time-varying bank asset volatility, and obtained a more reasonable model. It has analyzed the impact of time-varying volatility on deposit insurance pricing.
\end{abstract}

\section{Introduction}

Merton (1977) [1] proposed that bank deposit insurance pricing problem can be seen as an option pricing problem. Then Black and Scholes made famous BS formula, on the assumption that banks have assets of variance. At the same time, some scholars proposed new GARCH option pricing formula based on the time-varying volatility characteristics, and measured out the differences of deposit insurance prices based on both two frameworks, which reflect the impact of the time-varying volatility of bank assets on the pricing of deposit insurance.

Hai-long Liu (2018) [2] thinks that the same variance of the BS formula is doubtful. In the actual application process, he selected the Bank of America, JP Morgan Chase Bank and other five major listed banks whose assets were estimated deposit insurance rate and default probability based on the GARCH framework and the BS framework, now the results are shown in Table 1.

Table 1. Deposit insurance rates and bank asset volatility

\begin{tabular}{ccccc}
\hline Asset income Volatility & GARCH $(2009)$ & BS(2009) & GARCH(2010) & BS(2010) \\
\hline Bank of America & 0.0045 & 0.1184 & 0.0022 & 0.0805 \\
\hline JP Morgan Chase Bank & 0.0031 & 0.0925 & 0.0032 & 0.0634 \\
\hline Wells Fargo Bank & 0.0067 & 0.1671 & 0.0041 & 0.1237 \\
\hline United Bank & 0.0065 & 0.1274 & 0.0037 & 0.1232 \\
\hline New York Mellon Bank & 0.0071 & 0.1766 & 0.003 & 0.1251 \\
\hline
\end{tabular}

From the above analysis, it is not difficult to see that between 2009 and 2010, whether it is the bank asset volatility or the risk of default risk as an indicator to measure the price of deposit insurance, the value calculated by the BS framework is significantly higher than the GARCH framework.

However, the concern is that BS model theory is based on the fluctuating rate of change of circumstances, but GARCH framework is based on the premise variable rate volatility, which is a contradiction in the only prerequisite volatility, so it seems that the models cannot be established at the same time, and the research conducted by scholars ignores the proof process of the premise, so the authenticity of the conclusions needs to be verified. The key to solving this problem is to explain whether the volatility of bank assets has changed. If it is proved that the volatility is constant, then the GARCH model has problems; if the volatility is time-varying, it is wrong to re-use the deposit insurance rate calculated based on the BS model under the premise that the volatility is unchanged. Finally, we can come to a conclusion that BS model and GARCH model which applied in the 
calculation of the deposit insurance premium rate are more reasonable after considering asset volatility.

Therefore, the main part of this article calculated the asset volatility on the level of listed banks, selected China Everbright Bank, China Merchants Bank and other 16 listed banks in 2014 as a research object, using the week yields indicator data, respectively solving the volatility of its asset size of each year between 2014 to 2018 this year to verify the time-varying volatility of bank assets.

\section{Literature review}

Since Merton (1977) [1] proposed the deposit insurance pricing model, many scholars at home and abroad have studied the issue of deposit insurance pricing. This paper focuses on foreign and domestic literature, focusing on two big problems about the pricing methods of deposit insurance and the influencing factors of deposit insurance prices.

Foreign scholars believe that the mainstream deposit insurance pricing methods are the expected loss pricing model and the option pricing model. The option pricing method was first proposed by Merton (1977) [1] as an option pricing method for deposit insurance as a put option with bank assets as the subject matter, and deposit insurance based on Black-Scholes option pricing theory. This approach is a more mature approach than the expected loss pricing model. However, since the Merton (1977) [1] model does not consider the issue of dividends, Godin et al (2019) [3] developed novel and intuitive risk-neutral measures that can incorporate regime risk-aversion in a simple fashion and which do not lead to such path-dependence side effects.

There are also many scholars regarded to the pricing of deposit insurance made out of the study. By combining the capital extension and the regulatory tolerance, the capital extension deposit insurance pricing model under supervision and tolerance was given. There are many literatures on the impact of default risk on deposit insurance pricing. Xue-zhi Qin et al (2012) [4] established a deposit insurance pricing model for related defaults between banks within different loss-bearing layers. Many scholars believe that the volatility remains unchanged, but Yong-dong Shi (2017) [5] argued that the Brownian motion under time-varying volatility can describe the dynamic characteristics of financial markets more clearly and he uses the GARCH family model added the time-varying Hurst index in the Brownian motion environment.

Through the review of the previous literature, we know that the two popular deposit insurance pricing methods are BS and GARCH, in addition, we also know a series of factors that may affect the price of deposit insurance, including moral hazard, regulatory tolerance, default risk, and bank assets correlation, and asset volatility, in the sort of asset volatility and bank deposit insurance pricing studies, we can see whether the asset volatility variable scholars exist obvious differences, some scholars believe that the asset volatility is time-varying, it is advocated to use the BS formula to determine the deposit insurance rate. Some scholars believe that the asset volatility is time-varying, and that the BS formula has problems, and that the GARCH formula should be used to measure the deposit insurance price. Some scholars have revised the BS model, and some scholars have used the BS formula and the GARCH formula to evaluate the asset volatility and the deposit insurance price, and compared the results of the two models to obtain a comparison to draw the conclusion mentioned above that the asset volatility, default probability and deposit insurance rate calculated under the BS framework mentioned above are significantly higher than the conclusions of the GARCH framework. It is obvious that the authenticity of this conclusion needs to be verified. The key to solving this problem is to explain whether the volatility is variable. Therefore, the empirical part of this paper will focus on verifying the time-varying of bank assets, thus indicating whether both the BS model and the GARCH model can be used to determine the deposit insurance price. 


\section{Empirical analysis}

\subsection{Sample selection and data source}

To verify the law of return on bank assets fluctuate irregularly. This paper selected listed Banks as the research object. We focused on the volatility of return on assets of listed Banks from 2014 to 2018. To ensure the data integrity of observation samples, listed banks such as Shanghai Bank and Hangzhou Bank, which have been listed for less than five years, were excluded from the selection process of listed banks. Data from this study are all from Flush website. After screening the sample data, we obtained sixteen listed banks.

\subsection{Variable selection and research methods}

The research method adopted in this paper is to derive the weekly index data of the profit rate in each listed bank's historical transaction displayed on the website, focusing on the three data of time, opening and closing. By using the logarithmic rate of return formula of the stock price, we calculated the weekly yield of each bank between 2014 and 2018, selected the standard deviation as the index of our statistical volatility and used the STDEVA function in EXCEL to calculate the annual asset return volatility of the above 16 listed banks during the period from 2014 to 2018 and to summarize them.

In order to further explain the problem of variable volatility, this paper has developed a completely new definition as indicators (where Max represents the highest rate of return for each listed bank between 2014 and 2018, and Min corresponds to the lowest value of the rate of return), in the hope that the calculation of its specific value will clearly reflect the listed bank's Fluctuation pattern of return on assets. A summary of the volatility of the return on assets of the above banks and their Max/Min*100\% for past five years is shown in Table 2.

Table 2 List of listed bank asset volatility in the past five years

\begin{tabular}{ccccccc}
\hline Bank Name & 2014 & 2015 & 2016 & 2017 & 2018 & $\mathrm{Max} / \mathrm{Min} * 100 \%$ \\
\hline BJBANK & 0.0443 & 0.0651 & 0.0247 & 0.0285 & 0.0221 & 294.21 \\
ICBC & 0.0325 & 0.0459 & 0.0195 & 0.0257 & 0.0368 & 235.84 \\
CEB & 0.0516 & 0.0631 & 0.0307 & 0.0175 & 0.0270 & 360.95 \\
HXBANK & 0.0425 & 0.0619 & 0.0357 & 0.0355 & 0.0263 & 235.70 \\
CCB & 0.0391 & 0.0475 & 0.0267 & 0.0264 & 0.0441 & 180.32 \\
COMM & 0.0472 & 0.0615 & 0.0202 & 0.0202 & 0.0211 & 304.07 \\
CMBC & 0.0555 & 0.0505 & 0.0267 & 0.0220 & 0.0376 & 252.68 \\
NJCB & 0.0431 & 0.0656 & 0.0979 & 0.0619 & 0.0407 & 240.44 \\
NBBANK & 0.0432 & 0.0772 & 0.0368 & 0.0433 & 0.0357 & 216.04 \\
ABC & 0.0368 & 0.0419 & 0.0200 & 0.0224 & 0.0313 & 209.96 \\
SPABANK & 0.0444 & 0.0565 & 0.0374 & 0.0396 & 0.0462 & 151.04 \\
SPDB & 0.0390 & 0.0470 & 0.0330 & 0.0297 & 0.0231 & 203.32 \\
CIB & 0.0403 & 0.0550 & 0.0226 & 0.0226 & 0.0237 & 244.05 \\
CMB & 0.0360 & 0.0453 & 0.0307 & 0.0379 & 0.0373 & 147.45 \\
BOC & 0.0375 & 0.0550 & 0.0275 & 0.0197 & 0.0242 & 278.82 \\
CITIC & 0.0607 & 0.0588 & 0.0391 & 0.0253 & 0.0313 & 240.31 \\
\hline
\end{tabular}

Source of data: http://www.10jqka.com.cn

In the meantime, another question is whether we need to consider what factors led to the bank's return on assets listed showing a clear trend fluctuation within five years. Therefore, this paper introduces four major financial indicators: listed company's total market capitalization, earnings per share (EPS), net assets per share and turnover rate. The total market value refers to the total number of shares multiplied by the value of the current share price. It is used to reflect the size of the market. Earnings per share, also known as earnings per share, refers to the ratio of net profit to total equity. Another profitability indicator similar to EPS is the net asset value per share, which is compared with the total number of shares obtained by the shareholders' equity, reflecting how much asset value of the shares included. In addition, the "actual turnover rate" is often used to reflect the liquidity of stocks. The calculation formula is: actual turnover rate $=$ volume / free tradable shares $* 100 \%$, the 
stronger the turnover rate of the stock indicates the greater the trading volume of the stock, and its stock price fluctuations may also be greater.

To facilitate comparative analysis, the market capitalization distribution maps of the top ten listed banks and other banks, the total market capitalization of the listed banks and the turnover rate distribution map are listed banks per net assets and EPS distribution, the results shown in Fig 1,2.

The value of Max/Min*100\% of China Everbright Bank is 360.95, it ranks first among all listed banks with the highest volatility.

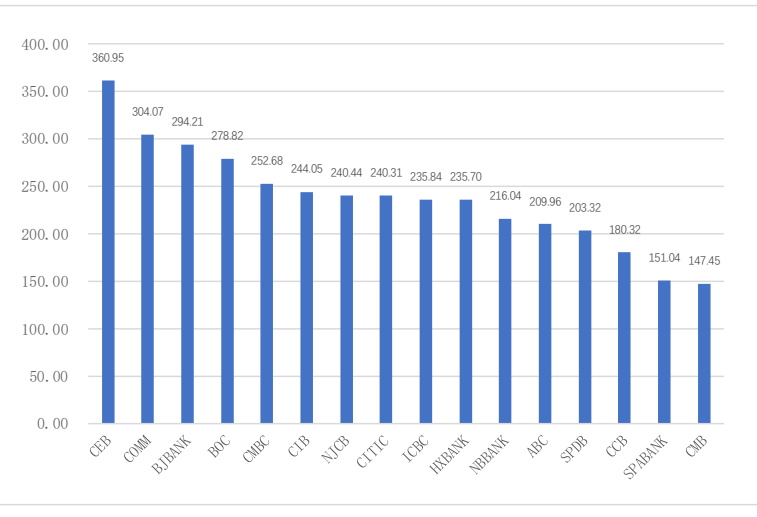

Fig1 Asset volatility max/min of listed banks

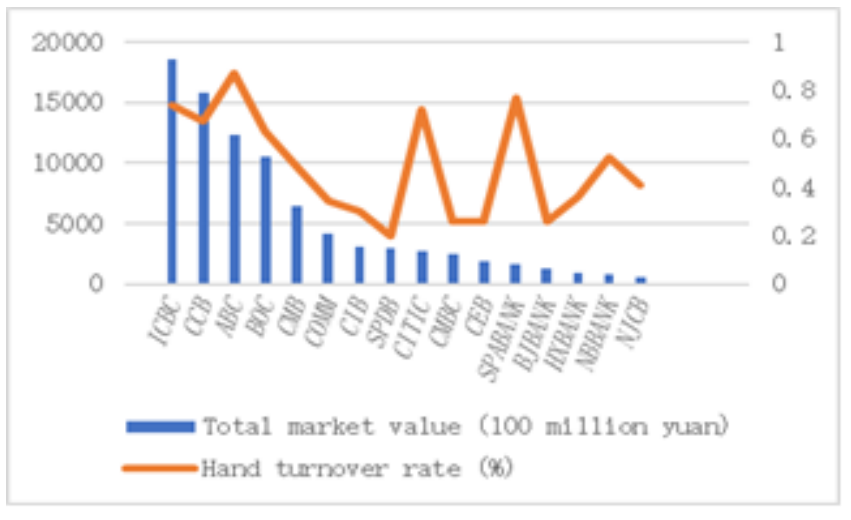

Fig 2 Total market capitalization and turnover rate

\section{Conclusions}

Through the above analysis, we can clearly recognize the time-varying characteristics of bank asset returns, which is contrary to the same variance of the BS model. In this case, the original BS model is still used to measure bank asset fluctuations. The rate is not accurate, and the corresponding bank deposit insurance price will also have a large deviation, which will bring greater risks. Because the BS and GARCH are based on different assumptions, it cannot be simultaneously compared. Now through the empirical analysis of this paper, we can conclude that the bank's asset volatility is timevarying, so we can have a firm grasp that GARCH is more reasonable than B-S. And the level of bank asset volatility at each stage should be calculated through the calculation of it to further develop a reasonable and effective bank deposit insurance price.

\section{Acknowledgment}

This research was financially supported by the National Natural Science Foundation of China (Grant NO. 71171128) and the Shanghai University's horizontal project (Project name: company convertible bond pricing method and its application).

\section{References}

[1] Merton RC, An Analytic Derivation of the Cost of Deposit Insurance and Loan Guarantees, Journal of Banking and Finance, vol1, pp.3-11, 1977.

[2] Hai-long Liu, Rui Li, Jin-jian Yuan, Deposit insurance pricing under GARCH, Finance Research Letters, vol26, pp.242-249, 2018.

[3] Frédéric Godin, Van Son Lai, Denis-Alexandre Trottier, Option pricing under regime-switching models: Novel approaches removing path-dependence, Insurance: Mathematics and Economics, vol 87, pp. 130-142, 2019.

[4] Xue-Zhi Qin, Xiao-lin Zhang, Kang Zhang, Consider the deposit insurance liability tiered pricing associated bank defaults, .Journal of Systems Management, vol21, pp. 6-12, 2012. 
[5] Yong-dong Shi, Hang Cheng, Guang-tao Wang, Ttime-varying fraction of European Option Pricing under GARCH family of Brownian motion, Systems Engineering Theory and Practice, vol37, pp. 2527-2538, 2017. 